\title{
Carbon nanospheres synthesized via solution combustion method: their application as an anode material and catalyst for hydrogen production
}

\author{
Vivek Dhand ${ }^{1}$, M Venkateswer Rao², J. S. Prasad ${ }^{3}$, Garima Mittal ${ }^{1}$, Kyong Yop Rhee ${ }^{1, \star}$, \\ Hyeon Ju Kim ${ }^{4}$ and Dong Ho Jung ${ }^{4}$ \\ ${ }^{1}$ Department of Mechanical Engineering, College of Engineering, Kyung Hee University, Yongin 446-701, Korea \\ ${ }^{2}$ Damascus Fortune Technologies Pvt Ltd., Sreeniketan No. 21, Plot\#12, Sector-1, Khanda Colony, New Panvel, Navi Mumbai 410206, India \\ ${ }^{3}$ CEN, IST, Jawaharlal Nehru Technological University, Kukatpally, Hyderabad 500 085, India \\ ${ }^{4}$ Seawater Utilization Plant Research Center, Korea Research Institute of Ships and Ocean Engineering, Daejeon 305-600, Korea.
}

\section{Article Info}

Received 12 May 2014

Accepted 2 July 2014

*Corresponding Author

E-mail: rheeky@khu.ac.kr

Tel: $+82-31-201-2565$

\section{Open Access}

DOI: http://dx.doi.org/

10.5714/CL.2014.15.3.198

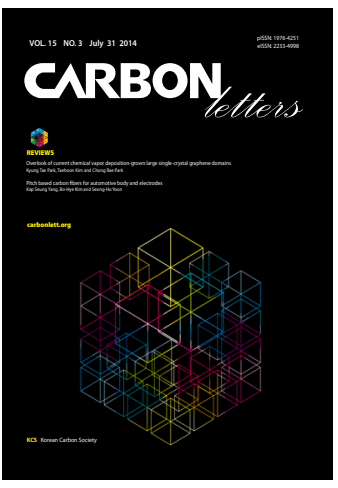

http://carbonlett.org

pISSN: $1976-4251$

elSSN: 2233-4998

Copyright $\odot$ Korean Carbon Society

\begin{abstract}
Amorphous agglomerates of carbon nanospheres (CNS) with a diameter range of 10-50 nm were synthesized using the solution combustion method. High-resolution transmission electron microscopy (HRTEM) revealed a densely packed high surface area of $\mathrm{SP}^{2}$-hybridized carbon; however, there were no crystalline structural components, as can be seen from the scanning electron microscopy, HRTEM, X-ray diffraction, Raman spectroscopy, and thermal gravimetric analyses. Electrochemical and thermo catalytic decomposition study results show that the material can be used as a potential electrode candidate for the fabrication of energy storage devices and also for the production of free hydrogen if such devices are used in a fluidized bed reactor loaded with the as-prepared CNS as the catalyst bed.
\end{abstract}

Key words: solution combustion, carbon nanospheres, cyclic voltammetry, hydrogen, surface area

\section{Introduction}

Carbon nanospheres (CNS) are circular carbons bearing concentric graphitic layers within the surface. Nanoscale carbon spheres are typically $10-50 \mathrm{~nm}$ in diameter and have high specific surface area [1]. CNS are a material that is now being explored for its novel chemical, physical, and biological applications. CNS are produced as an impurity in many processes like flame synthesis, arc discharge, laser ablation, and chemical vapor deposition [2-6]. Recently, combustion-generated particles have gained significant interest due to their direct health and environmental effects $[7,8]$. In recent years, researchers have focused their attention on fine and ultrafine particles with sizes down to a few nanometers; such particles are most likely to cause the observed effects [7,9]. Broadly speaking, fine and ultrafine particles comprise two main classes of compounds: nanospheres of organic carbon (NOC), characterized by a size range of 1-10 nm, and soot particles, with sizes in the range 10-100 nm. NOCs usually precede and accompany soot formation but have also been found in flames operated in rich conditions well below the soot limit [10]. As discussed, these nanospheres are now being tested for their toxicity effects on life forms and their catalytic activity in metallurgy, as drug delivery systems and energy devices, and for potential uses in many other areas. The present paper briefly discusses the synthesis and the quality of these nanospheres produced by solution combustion process and assesses their potential for use in catalysis and energy storage sectors. 


\section{Materials and Methods}

All the materials procured were of analytical grade and were utilized without any purification throughout the study. Citric acid, ethanol, and nitric acid were purchased from Sigma-Aldrich and from Merck, India. Camphor was purchased from the local Indian market.

\subsection{Methodology}

According to the reaction, the stoichiometric amount of citric acid, nitric acid, and a solution of dissolved camphor in ethanol were mixed. The mixture was then kept in a furnace pre-maintained at $350^{\circ} \mathrm{C}$. The complete reaction continued for $20 \mathrm{~min}$ with the evolution of white fumes followed by brownish nitrous oxide fumes. On further heating, a slurry was formed that auto ignited; this finally resulted in the formation of a black powder. The obtained powder was then heated further for $1 \mathrm{~h}$ at a temperature of $400^{\circ} \mathrm{C}$ in a nitrogen environment to yield pure spherical nanoparticles of carbon. The powder was then analyzed to determine its crystallinity, morphology, quality, thermal stability, surface area, and electrochemical property using scanning electron microscopy (SEM), transmission electron microscopy (TEM), X-ray diffraction (XRD), Raman, thermal gravimetric analysis (TGA), Brunauer-Emmett-Teller (BET), and cyclic voltammetry (CV).

\section{Results and Discussion}

\subsection{SEM analysis}

The samples were analyzed using a field emission (FE)-SEM (LEO SUPRA 55; Carl Zeiss, Germany). The FE-SEM (Fig. 1) shows a cluster of densely populated amorphous soot at a higher magnification as spherical particles. The average diameter of each particle is around $50 \mathrm{~nm}$.

\subsection{TEM analysis}

A high-resolution (HR) TEM (FE-HRTEM JEM2100F) operated at $200 \mathrm{kV}$ was used for the TEM analysis. Figs. 2 and 3 show the TEM and HRTEM images, respectively, of the agglomerated CNS with sizes varying between 40-50 $\mathrm{nm}$. In the higher resolution image, it can be seen that the spheres are made of several layers of graphitic rings that are heavily distorted and compact. Similar results for CNS have been reported by several researchers $[3,11,12]$. Technically, for the soot structure and shape to be in the nanophase range of 10-50 $\mathrm{nm}$ depends on the fuel type, temperature, combustion kinetics, and chemistry [13]. Vander Wal et al. $[14,15]$ sampled soot particles produced from an engine and other units directly on TEM grids. These particles are similar in morphology and size, exhibit an amorphous nature, and are predominantly composed of turbostatic and fullerenic carbon.

\subsection{XRD analysis}

The XRD and crystal data studies were done using a Bruker AXS-D-8 Discover X-ray Diffractometer. The XRD image (Fig.

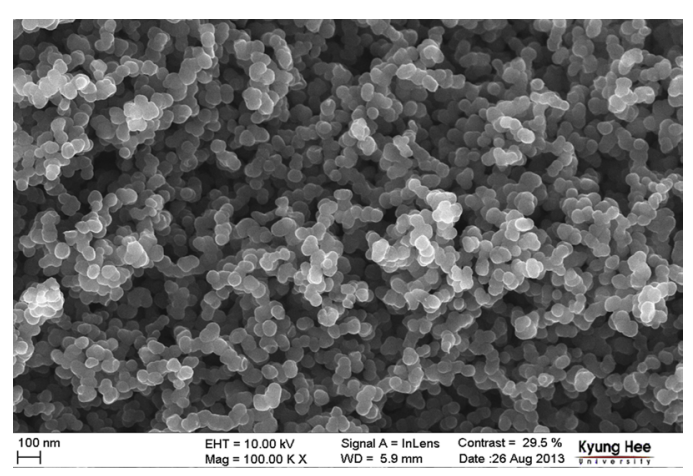

Fig. 1. Scanning electron microscopy image of carbon nanospheres produced via solution combustion method.

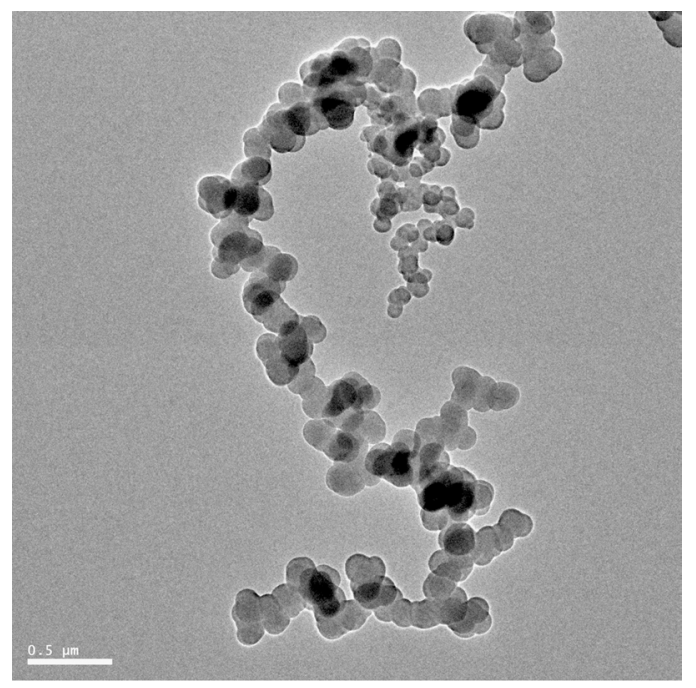

Fig. 2. Transmission electron microscopy image of carbon nanospheres produced via solution combustion method.

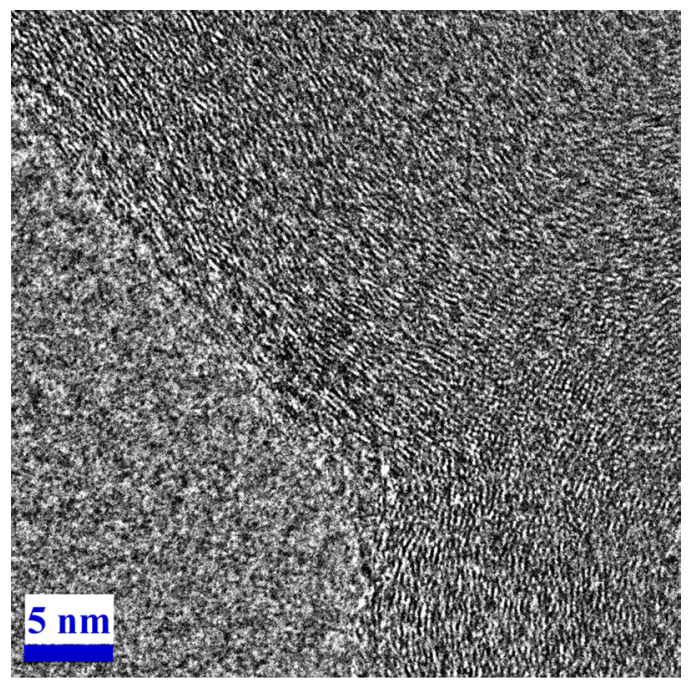

Fig. 3. High-resolution transmission electron microscopy image of carbon nanospheres, produced via solution combustion method, displaying the highly distorted concentric graphitic layers. 


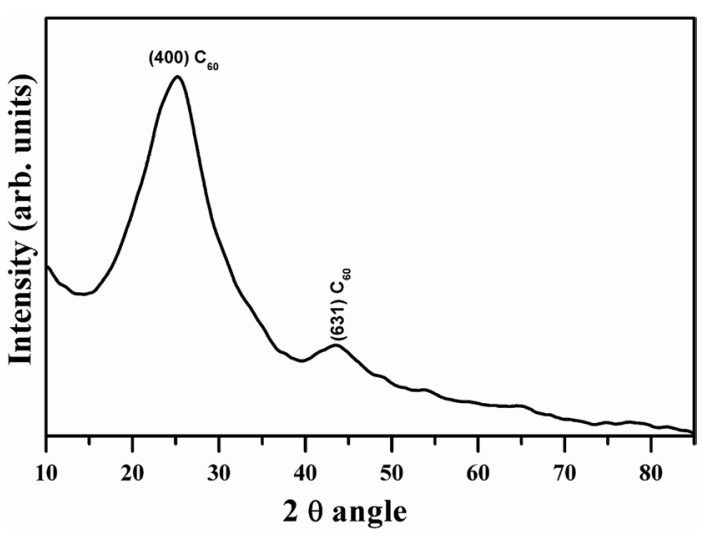

Fig. 4 X-ray diffraction image of carbon nanospheres, produced via solution combustion method, displaying the presence of fullerene molecule peak.

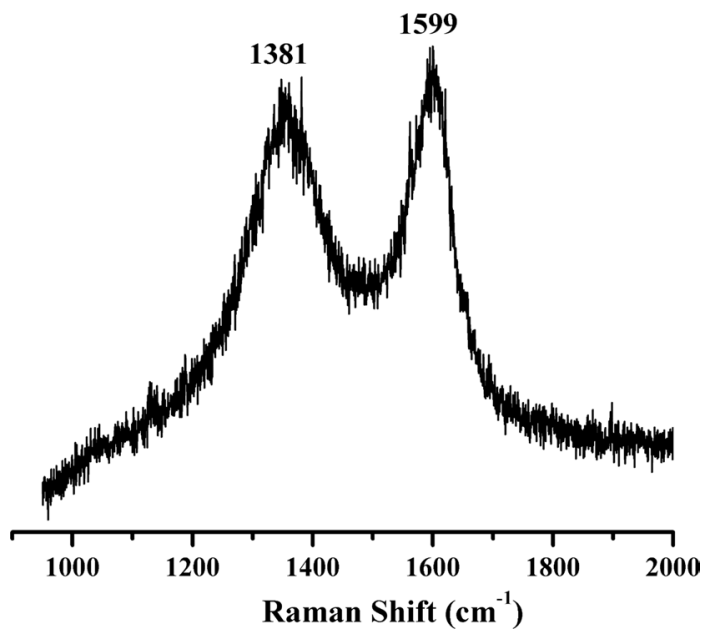

Fig. 5. Raman spectrum of carbon nanospheres produced via solution combustion method.

4) shows no strong crystalline structures, but has a vivid amorphous broadening in the peak at a $2 \theta$ angle of $25.2^{\circ}$. A total of two peaks were identified, of which the first peak at a $2 \theta$ angle of $25.2^{\circ}$ matches with the presence of the $\mathrm{C}_{60}$ lattice oriented along the (400) plane of its axis [JCPDF \# 79-1715]. A small intensity reflection of the $\mathrm{C}_{60}$ at a $2 \theta$ angle of $43.64^{\circ}$ with (002) orientation shows a primitive lattice and a hexagonal system [JCPDF \# 79-1715].

\subsection{Raman analysis}

The nanocarbon sample was analyzed using a Jasco Raman spectrometer equipped with a charge-coupled device detector at a wavelength of $532 \mathrm{~nm}$ from 1000 to $2000 \mathrm{~cm}^{-1}$. The spectrum (Fig. 5) is similar to that of a strongly disordered SP2 graphite layer. Since the Raman spectrum of soot has a broad D- band at around $1381 \mathrm{~cm}^{-1}$, a contribution from amorphous carbon cannot be excluded. With this type of broadening in the $\mathrm{D}$ band, it can be concluded that the dominant fraction of the soot consists mainly of disordered fullerenic turbostatic carbon. In contrast,

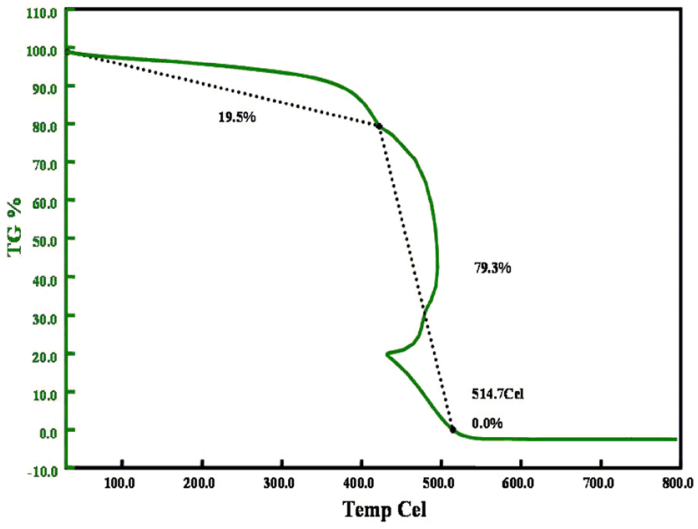

Fig. 6. Thermogram of carbon nanospheres produced via solution combustion method.

the width of the $\mathrm{G}$ peak at $1599 \mathrm{~cm}^{-1}$ decreases as the size of the carbon sphere decreases in the sample. The ratio of the intensities of the $\mathrm{D}$ and $\mathrm{G}$ bands gives an estimation of the quality of the sample. In our case, this ratio was found to be 0.96 , which designates the sample as turbostatic, as was observed.

\subsection{TGA analysis}

Thermal analysis of the sample was carried out using a thermal analyzer (TGA Q5000 IR/SDT Q600 (TA) at a rate of $10^{\circ} \mathrm{C} /$ min in the presence of air. From the thermogram (Fig. 6) we can observe the first step $\left(\sim 400-500^{\circ} \mathrm{C}\right)$, which corresponds to the combustion of the amorphous carbon or to degenerated graphitic carbons. In the second step the weight loss at higher temperatures $\left(\geq 500^{\circ} \mathrm{C}\right)$ corresponds to combustion of outer layers of the CNS with varying degrees of thickness and graphitization, as can be observed in the HRTEM image $[16,17]$. The weight trace at $\sim 430^{\circ} \mathrm{C}$ suddenly shifts backwards on the abscissa and then continues in its normal forward motion, which is generally attributed to the combustion of the individual graphitic layers within the CNS. During this process the spherical particles start burning the outer layers, which process releases a significant amount of heat in a quick manner, which further results in the quick dissipation of heat before the next layer starts degenerating. Hence such kinds of peaks are often found in samples with several layers of carbon or in the presence of a metallic catalyst $[18,19]$.

\subsection{BET surface area}

The surface area of CNS was assessed using a SMART SORB 92 BET surface area analyzer at a regeneration temperature of $200^{\circ} \mathrm{C}$ for $2 \mathrm{~h}$ with $\mathrm{N}_{2}$ purging. The surface area of the CNS was $141.65 \mathrm{~m}^{2} / \mathrm{g}$.

\section{Applications}

Two application modules (Fig. 7) were employed to showcase the use of CNS as an anode material for prospective energy devices and also as an effective catalytic material for the pro- 

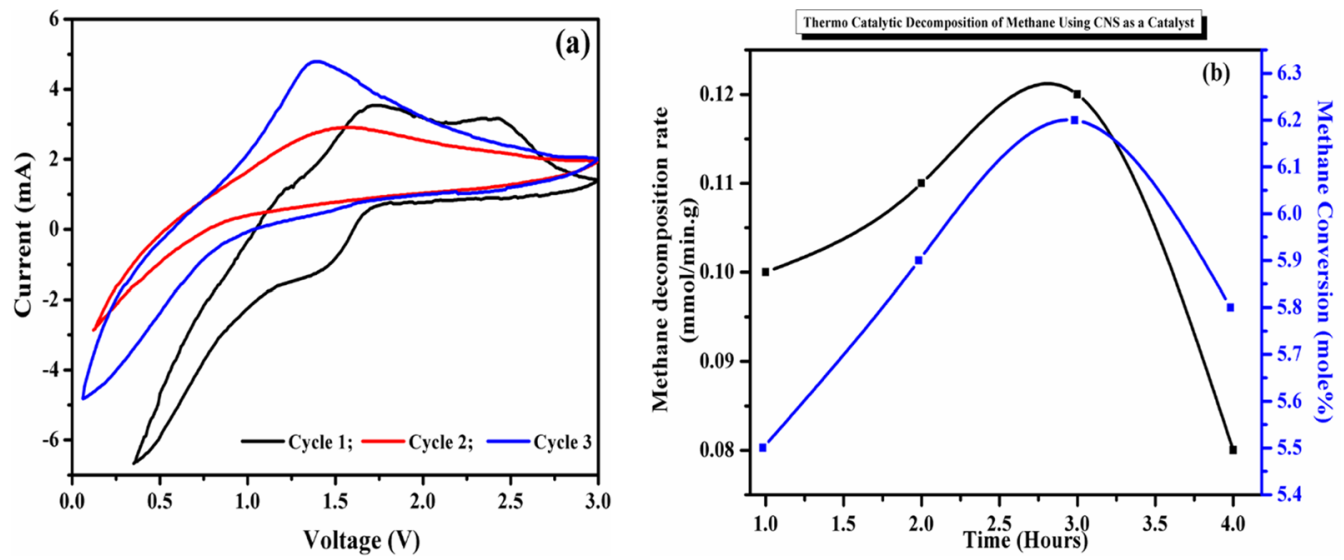

Fig. 7. (a) Cyclic voltammetry of electrode fabricated using the as-prepared carbon nanospheres (CNS), (b) thermo catalytic decomposition of methane using CNS as a catalyst.

duction of hydrogen via thermo catalytic decomposition (TCD) of methane. The following section deals with the application of CNS in brief.

\subsection{Electrode preparation}

The anode was fabricated by doctor blade coating. The coating slurry was prepared by mixing synthesized carbon and polyvinylidene difluoride at a weight ratio of 90:10 in N-methyl pyrrolidine. The slurry was poured over copper foil and dried at room temperature for $24 \mathrm{~h}$ and at $120^{\circ} \mathrm{C}$ for $5 \mathrm{~h}$ using a hot air oven. Commercially available lithium metal was applied as the cathode. Li ion cells were assembled in a 2032 coin cell by sandwiching the separator between the lithium cathode and the carbon anode along with a 1M LiPF6 electrolyte in ethylene carbonate: diethyl carbonate $(1: 1, \mathrm{vol} \%)$. All cells were assembled in a glove box filled with argon gas.

\subsection{Electrochemical analysis}

CV analysis using a Princeton VersaSTAT-3 instrument was carried out between $0.1 \mathrm{~V}$ and $3 \mathrm{~V}$ on the carbon working electrode, with a counter and reference electrodes of lithium at a scan rate of $2 \mathrm{mV} / \mathrm{s}$. From the $\mathrm{CV}$, the lithiation and delithiation mechanism of the prepared electrode material was observed. The lithiation and delithiation mechanism is highly dependent on the structural characteristics, such as the degree of graphitization, the pore size and shape, and the functional groups, since these factors are responsible for differences in the diffusion rate and reversibility of the lithium ions during the reaction [20]. The graph (Fig. 7a) shows the CV curves of the electrodes made of CNS for 3 scans. It can be observed that there is an increasing cathodic peak range starting from $0.7-2.1 \mathrm{~V}$ for cycles 2 and 3 , whereas cycle 1 displays a separate and very narrow to broad trend from 1.2 V onwards. The initial trend is common and indicates the insertion of lithium ions in the carbonaceous substances and the formation of a solid electrolyte interface layer [20]. The removal of lithium is observed over a wide potential range of 0.6-2.1 V, displaying a broader and wavy anodic range in the $\mathrm{CV}$. In this high range cycle 1 displays a different $\mathrm{CV}$, exhibit- ing late insertion of lithium ions and wavy anodic peaks around 1.7 and $2.5 \mathrm{~V}$; also, from the cycle 3 and cycle 2 peak shapes, a similar upward trend at around $1.4 \mathrm{~V}$ can be observed, which indicates the existence of a secondary lithium storage reaction. The presence of the large surface area of CNS may be attributed to the exceptional electrochemical performance [20].

\subsection{TCD of methane}

The as-prepared CNS were utilized to study the TCD of methane for free hydrogen production as a catalyst (Fig. 7b). The decomposition reactor was fed with $1 \mathrm{~g}$ of purified CNS and the reaction was allowed to proceed at $850^{\circ} \mathrm{C}$ and 1 atmosphere, under which conditions undiluted methane ( 99.99 mole\%) was passed with a flow rate of $54 \mathrm{sccm}$ over the CNS; the rate of decomposition of the methane gas to hydrogen was found to be $0.12 \mathrm{milli} \mathrm{mole} / \mathrm{min} / \mathrm{gram}$, i.e. the total methane per pass conversion was found to be 6-7 mole $\%$ with the product gases in the reactor containing 12-13 mole $\%$ of hydrogen. The surface areas of the CNS before and after the reaction were $141.65 \mathrm{~m}^{2} / \mathrm{g}$ and $85.16 \mathrm{~m}^{2} / \mathrm{g}$ respectively

\section{Conclusions}

Solution combustion as a process has an immense capacity to produce CNS in bulk quantities. Solution combustion technology offers a scalable, dry technology for synthesis of high purity nanoparticles with closely controlled characteristics. Presently, CNS are slowly gaining interest in the fields of drug delivery systems, hydrogen storage, catalysis industrial composites, and electrochemical devices.

\section{Acknowledgements}

This work was financially supported by the National R\&D project of "Development of Energy Utilization Technology of Deep Sea Water Resource" supported by the Ministry of Oceans and Fisheries of the Republic of Korea. 


\section{References}

[1] Zhao H, Tian J, Quan X. A graphene and multienzyme functionalized carbon nanosphere-based electrochemical immunosensor for microcystin-LR detection. Colloids Surf B, 103, 38 (2013). http:// dx.doi.org/10.1016/j.colsurfb.2012.10.010.

[2] Dhand V, Prasad JS, Rao MV, Mahesh KN, Anupama L, Himabindu V, Anjaneyulu Y, Raju VS, Sukumar AA. Design and development of flame reactor unit for carbon nanorods (CNRs) production. Ind J Eng Mater Sci, 14, 235 (2007).

[3] Dhand V, Prasad JS, Rao MV, Bharadwaj S, Anjaneyulu Y, Jain PK. Flame synthesis of carbon nano onions using liquefied petroleum gas without catalyst. Mater Sci Eng C, 33, 758 (2013). http:// dx.doi.org/10.1016/j.msec.2012.10.029.

[4] Rao MV, Dhand V, Prasad JS, Mahesh KN, Himabindu V, Yerramilli A, Sreedhar B. In situ lithium intercalation of carbon nanorods using flame synthesis. Compos Sci Technol, 70, 255 (2010). http://dx.doi.org/10.1016/j.compscitech.2009.10.016.

[5] Landström L, Márton Z, Boman M, Heszler P. Monitoring nanoparticle formation during laser ablation of graphite in an atmospheric-pressure ambient. Appl Phys A, 79, 537 (2004). http://dx.doi. org/10.1007/s00339-003-2364-5.

[6] Surovikin VF, Shaitanov AG. Formation and growth of dispersed carbon particles during pyrolysis of ethylene, benzene, and naphthalene in a reflected shock wave. Combust Explos Shock Waves, 43, 442 (2007). http://dx.doi.org/10.1007/s10573-007-0060-z.

[7] D'Anna A, Commodo M, Violi S, Allouis C, Kent J. Nano organic carbon and soot in turbulent non-premixed ethylene flames. Proc Combust Inst, 31, 621 (2007). http://dx.doi.org/10.1016/j. proci.2006.07.062

[8] Dockery DW, Pope CA 3rd, Xu X, Spengler JD, Ware JH, Fay ME, Ferris BG Jr., Speizer FE. An association between air pollution and mortality in six U.S. cities. N Engl J Med, 329, 1753 (1993). http:// dx.doi.org/10.1056/nejm199312093292401.

[9] Oberdörster G, Sharp Z, Atudorei V, Elder A, Gelein R, Lunts A, Kreyling W, Cox C. Extrapulmonary translocation of ultrafine carbon particles following whole-body inhalation exposure of rats. J Toxicol Environ Health A, 65, 1531 (2002). http://dx.doi. org/10.1080/00984100290071658.

[10] Minutolo P, Gambi G, D'Alessio A, Carlucci S. Spectroscopic characterisation of carbonaceous nanoparticles in premixed flames. Atmos Environ, 33, 2725 (1999). http://dx.doi.org/10.1016/S1352-

\section{0(98)00330-6}

[11] Kang J, Li OL, Saito N. Synthesis of structure-controlled carbon nano spheres by solution plasma process. Carbon, 60, 292 (2013). http://dx.doi.org/10.1016/j.carbon.2013.04.040.

[12] Sawant SY, Somani RS, Panda AB, Bajaj HC. Formation and characterization of onions shaped carbon soot from plastic wastes. Mater Lett, 94, 132 (2013). http://dx.doi.org/10.1016/j.matlet.2012. 12.035 .

[13] Vander Wal RL, Tomasek AJ. Soot nanostructure: dependence upon synthesis conditions. Combust Flame, 136, 129 (2004) http://dx.doi.org/10.1016/j.combustflame.2003.09.008.

[14] Vander Wal RL, Bryg VM, Huang CH. Insights into the combustion chemistry within a gas-turbine driven auxiliary power unit as a function of fuel type and power level using soot nanostructure as a tracer. Fuel, 115, 282 (2014). http://dx.doi.org/10.1016/j. fuel.2013.07.011.

[15] Vander Wal RL, Strzelec A, Toops TJ, Stuart Daw C, Genzale CL. Forensics of soot: C5-related nanostructure as a diagnostic of in-cylinder chemistry. Fuel, 113, 522 (2013). http://dx.doi org/10.1016/j.fuel.2013.05.104.

[16] Li Z, Zhao B, Liu P, Zhao B, Chen D, Zhang Y. Synthesis of highquality single-walled carbon nanotubes by high-frequency-induction heating. Physica E, 40, 452 (2008). http://dx.doi.org/10.1016/j. physe.2007.06.062.

[17] Triantafyllidis KS, Karakoulia SA, Gournis D, Delimitis A, Nalbandian L, Maccallini E, Rudolf P. Formation of carbon nanotubes on iron/cobalt oxides supported on zeolite-Y: effect of zeolite textural properties and particle morphology. Microporous Mesoporous Mater, 110, 128 (2008). http://dx.doi.org/10.1016/j.micromeso.2007.10.007.

[18] Soloiu V, Lewis J, Yoshihara Y, Nishiwaki K. Combustion characteristics of a charcoal slurry in a direct injection diesel engine and the impact on the injection system performance. Energy, 36, 4353 (2011). http://dx.doi.org/10.1016/j.energy.2011.04.006.

[19] Carvalho CT, Siqueira AB, Rodrigues EC, Ionashiro M. Synthesis, characterization and thermal behaviour of solid-state compounds of 2-methoxybenzoate with some bivalent transition metal ions. Eclét Quím, 30, 19 (2005). http://dx.doi.org/10.1590/S010046702005000400003.

[20] Wang YX, Chou SL, Liu HK, Dou SX. Reduced graphene oxide with superior cycling stability and rate capability for sodium storage. Carbon, 57, 202 (2013). http://dx.doi.org/10.1016/j.carbon.2013.01.064. 